Relato de Experiência - 559 -

\title{
DIÁLOGOS ENTRE A ARTE E A EDUCAÇÃO: UMA EXPERIÊNCIA NO ENSINO DA DISCIPLINA DE ADMINISTRAÇÃO EM SAÚDE
}

\author{
Maria Raquel Gomes Maia Pires ${ }^{1}$, Carla Aparecida Spagnol², Maria José Menezes Brito³, Maria Flávia de \\ Carvalho Gazzinelli ${ }^{4}$ Lívia Cozer Montenegro ${ }^{5}$
}

\footnotetext{
${ }^{1}$ Doutora em Política Social. Professor Adjunto da Escola de Enfermagem (EE) da Universidade Federal de Minas Gerais (UFMG). Minas Gerais, Brasil. E-mail: raquelgmp@enf.ufmg.br

${ }^{2}$ Doutora em Saúde Coletiva. Professor Adjunto da EE/UFMG. Minas Gerais, Brasil. E-mail: spagnol@enf.ufmg.br

${ }^{3}$ Doutora em Administração. Professor Adjunto da EE/UFMG. Minas Gerais, Brasil. E-mail: brito@enf.ufmg.br

${ }^{4}$ Doutora em Educação. Professor Adjunto da EE/UFMG. Minas Gerais, Brasil. E-mail: flavia@enf.ufmg.br

${ }^{5}$ Mestranda do Programa de Pós-graduação em Enfermagem da UFMG. Professor Adjunto da EE/UFMG. Minas Gerais, Brasil.

E-mail: livinhamontenegro@hotmail.com
}

\begin{abstract}
RESUMO: Relata-se a experiência do ensino da administração em saúde em conversas com as expressões artísticas no curso de graduação em enfermagem, mediadas pela obra - As Intermitências da Morte, de José Saramago. Teoriza-se sobre o desenvolvimento da autonomia, do potencial criativo e da capacidade de abstração na formação de enfermeiros por meio da interface entre a arte e a educação. Objetiva-se refletir sobre as possibilidades de aprendizagem a partir das expressões da arte, bem como analisar a experiência do ensino da gestão do Sistema Único de Saúde em diálogo com a arte e a educação. A vivência indica que a interface entre a produção acadêmica, a teorização das práticas, a criatividade, a abstração ética e estética produz sentidos de aprendizagem que ultrapassam a racionalidade instrumental, contribuindo para a formação de cidadãos e profissionais de saúde.
\end{abstract}

DESCRITORES: Enfermagem. Educação em enfermagem. Arte. Materiais de ensino. Administração em saúde.

\section{DIALOGUE BETWEEN ART AND EDUCATION: AN EXPERIENCE IN THE TEACHING OF HEALTH ADMINISTRATION CLASSE}

\begin{abstract}
ABTRACT: In this study is described an experience on teaching of health administration in a nursing graduation course, mediated by José Saramago's book titled - The Intermittency of the Death. It is discussed the autonomy development, the creativity potential and the abstraction capacity during the nursing graduation course, through the interface between art and education. Claiming to show the learning possibilities with the use of art expressions and analyzing the experience of teaching Public Health System management in dialogue with art and education, begins a theoretical reflection on health administration content with the art expression. The experience indicates that the interface between the academic production, the practice theory, the creativity, the ethical and aesthetical abstraction produces learning that goes beyond of the rationality instrumental, contributing to capacity citizens and health professionals.
\end{abstract}

DESCRIPTORS: Nursing. Nursing, education. Art. Teaching materials. Health administration.

\section{DIÁLOGOS ENTRE ARTE Y EDUCACIÓN: UNA EXPERIENCIA EN LA ENSEÑANZA DE LA ASIGNATURA ADMINISTRACIÓN EN SALUD}

\begin{abstract}
RESUMEN: En este estudio se describe una experiencia vivida en la enseñanza de la asignatura Administración en Salud, en el curso de enfermería, la cual fue mediada por el libro - Las Intermitencias de la Muerte de José Saramago. Se discute sobre el desarrollo de la autonomía, el potencial creativo y la capacidad de abstracción en la formación de enfermeros, a través de la interfaz entre arte y educación. Su objetivo es reflexionar sobre las posibilidades de aprendizaje usando las expresiones del arte, así como analizar la experiencia de la enseñanza de la gestión del Sistema Público de Salud en diálogo con el arte y la educación. La experiencia vivida indica que la interfaz entre la producción académica, la teorización de las prácticas, la creatividad, la abstracción ética y estética produce sentidos de aprendizaje que van más allá de la racionalidad instrumental, lo que contribuye a la formación de ciudadanos y profesionales de salud.
\end{abstract}

DESCRIPTORES: Educación. Educación en enfermería. Arte. Materiales de enseñanza. Administración en salud. 


\section{INTRODUÇÃO}

A formação de profissionais críticos e reflexivos é um dos avanços inscritos nas Diretrizes Curriculares Nacionais para os cursos de graduação da área da saúde. A educação de enfermeiros com qualificação técnica e política, com capacidade de tomar decisões, de empreender, de trabalhar em equipe, de lidar com incertezas e com a dinâmica da realidade, implica na inovação das estratégias pedagógicas, em mudanças curriculares e nas relações institucionais entre os serviços de saúde e as universidades. ${ }^{1}$ Diante do desafio, acredita-se que uma das possibilidades de inovação para as práticas reside na articulação profícua entre a arte e a educação. ${ }^{2-3}$

No caminho das mudanças previstas, esse artigo reflete sobre a experiência do ensino da administração em saúde, centrada na gestão do sistema e serviços de saúde, por meio de manifestações artísticas, no quarto período da graduação em enfermagem, da Escola de Enfermagem (EE) da Universidade Federal de Minas Gerais (UFMG). A partir da vivência de dois semestres, questiona-se e teoriza-se sobre o desenvolvimento da autonomia, do potencial criativo e da capacidade de abstração na formação de enfermeiros, em interface com a dimensão estética da educação. Tem-se como argumento central que a articulação entre a reflexão acadêmica, a teorização das práticas, a criatividade, a abstração ética e estética podem produzir sentidos de aprendizagem que ultrapassem a racionalidade instrumental contribuindo para a formação de cidadãos e profissionais de saúde. Objetiva-se refletir sobre as possibilidades de aprendizagem a partir das expressões da arte; bem como analisar a experiência do ensino da gestão do Sistema Único de Saúde (SUS) por meio do diálogo entre a arte e a educação.

Para viabilizar a interface entre os conteúdos da administração em saúde com as expressões da arte, propôs-se o Ciclo de debates: intermitências da morte e a gestão do SUS: diálogo entre Saramago e as políticas de saúde, evento de extensão aberto ao público, que se desenvolve ao longo da disciplina, mediada pela discussão da obra literária "As Intermitências da morte" . ${ }^{4}$ Realizam-se três atividades envolvendo os conhecimentos teóricos da área de saúde, o cinema e a literatura. Ao final, e na tentativa de sintetizar os aprendizados vividos, os alunos apresentam um diálogo reflexivo entre a obra literária e as políticas de saúde no Brasil, contemplando algum componente artístico. O evento visa ainda debater a universalidade do SUS no contexto de globalização econômica; refletir sobre os diversos sentidos da morte, com foco nas repercussões para a gestão das políticas de saúde e para a formação dos profissionais; bem como desenvolver as habilidades de abstração, sistematização de idéias, elaboração de projetos e criatividade como requisitos para a formação do profissional de saúde.

A participação dos profissionais e técnicos da Secretaria Municipal de Saúde de Belo Horizonte (SMSA-BH) não apenas na origem da proposta, como em todo o decorrer da experiência, propiciado pela boa articulação entre ensino e o serviço existente, é outro ponto exitoso a se destacar. Vale dizer que a disciplina é formada por cinco professores, mobiliza nas atividades práticas cinco distritos sanitários da SMSA-BH, incluindo cinco Centros de Saúde, cinco Unidades de Pronto-Atendimento, cinco Serviços de Especialidades e cinco Unidades Hospitalares. Orquestrar esse universo amplo de serviços e profissionais, envolve muitas atividades interinstitucionais prévias. Nesse sentido, todo cuidado se teve quando da implantação da iniciativa, que é inteiramente discutida e realizada em parceria com a SMSA-BH.

O texto está estruturado em três partes. Inicialmente faz-se uma discussão teórica sobre as vertentes emancipatórias do intermeio da arte com a educação. Em seguida, e a partir da teorização realizada, apresenta-se o relato e a discussão da experiência, em que se apontam caminhos para o ensino da administração em saúde pelas tramas do universo estético da educação. Ao final, registrase os principais resultados vivenciados até aqui, incluindo os desafios atuais e futuros.

\section{METODOLOGIA}

Trata-se de relato de experiência na qual se faz uma reflexão teórica da interface entre a arte e a educação para a formação dos sujeitos da aprendizagem, a partir da qual se teoriza sobre a vivência. Percorreu-se o seguinte caminho: utilizou-se o argumento central como eixo fundamental em torno do qual giraram as reflexões; empreendeu-se revisão bibliográfica nas principais bases de dados internacionais, através da Biblioteca Virtual em Saúde (BIREME), e a Scientific Electronic Library Online (SciELO), as palavras-chaves educação, educação em enfermagem, arte, ensino superior, materiais de ensino, ensino, administração em saúde e educação em enfermagem; inclúi-se publicações atualizadas sobre o tema, com autores clássicos da filosofia, da sociologia e da educação; 
desenvolveu-se observação das atitudes e da postura dos alunos a partir dos questionamentos, das argumentações, dos silêncios, das hesitações, das ênfases e dos gestos que surgiam nas atividades desenvolvidas na disciplina.

Utilizou-se diversas técnicas de ensino lúdico-pedagógicas e de articulação teoria-prática para o desenvolvimento da aprendizagem dos sujeitos. Além disso, o projeto de extensão articulado ao ensino, "Ciclo de debates: intermitências da morte e a gestão do SUS: diálogo entre Saramago e as políticas de saúde", subsidiou as atividades científico-culturais dos discentes. Nele ocorreram três eventos interligados. $\mathrm{O}$ primeiro utilizou a linguagem do cinema para debater comparativamente universalidade de sistemas de saúde, direito de cidadania frente a mercantilização da saúde. O segundo buscou na literatura de Saramago, ou na situação fictícia de suspensão temporária da morte num determinado país, inspirações das letras para os dilemas do SUS. No simpósio final que articula os momentos anteriores, aconteceu a mostra de produção dos alunos, expressando o diálogo entre a arte, a educação e a gestão do SUS. Nesse momento, fez-se uso das diversas manifestações artísticas, como o teatro, a dança, a música, o vídeo, a exposição de artes plásticas, o fantoche, dentre outros, todos encenados pelos graduandos. O prêmio "Jovem gestor do SUS", entregue ao melhor trabalho, foi criado para motivar a participação da turma.

\section{CONVERSAS ENTRE A ARTE E A EDU- CAÇÃO: EM BUSCA DA AUTONOMIA E DA CRIATIVIDADE NA FORMAÇÃO DE SUJEITOS CRÍTICOS}

Entrelaçar arte e educação significa produzir sentidos de aprendizagem que ultrapassem o mecanicismo da técnica, tão arraigada na formação dos profissionais de saúde. Visa-se transcender a razão instrumental, denunciada por teóricos da Escola de Frankfurt, em que o automatismo das idéias tende a aprisionar pensamentos de significado próprio. ${ }^{5-6}$ Insiste-se em abstrações que subvertam a rigidez da ordem, pela expressão do sentimento que se exprime por si e para além do que está posto. Essa parece ser a principal força motriz das manifestações artísticas, capazes de desencadear processos formativos dialógicos ${ }^{6-7}$ Para tanto, aposta-se num conhecimento que leve em conta o impossível do devir humano e a expressão de seu mundo sensível, conjugando transcendên- cia de espírito com racionalidade metódica para apreensão do real. Resgata-se aqui a hermenêutica do sujeito em Foucault, em que a relação entre os princípios socráticos do "cuidado de si", um "ocupar-si consigo mesmo", com o "conhece-te a ti mesmo", enquanto método de conhecimento, é condição para o acesso à verdade, numa busca de transformação espiritual e racional. ${ }^{8}$

Ensinar por meio da arte possibilita produzir experiências de aprendizagem não padronizáveis pela instrumentalidade da razão, incentivando processos criativos capazes de forjar sujeitos do saber e da liberdade. Tal intento se manifesta principalmente pela disposição da arte em produzir, em trazer à existência vivências susceptíveis de ser e de não ser, cujo princípio reside no artista. À guisa de uma ambiência teórica que auxilie o entendimento da expressão artística, entrelaçando abstração reflexiva com o cortejo ritual presente na etimologia da palavra theoria, fala-se em possíveis teorias fundadoras e de acompanhamento da arte. ${ }^{9}$ As fundantes constituiriam o objeto artístico, enquanto as de acompanhamento realizariam seu seguimento, seu comentário e sua crítica. Pelo caráter transcendente e incapturável da arte, tais construtos precisam ser entendidos em sentido movediço, costurados pelo entremeio da doxa, muito aquém do efêmero manifesto no elemento artístico. A doxa de que se fala inclui o cotidiano das percepções e dos sentidos de que se nutre a arte, imerso em opiniões, em crenças e em sombras sobre o real, tanto quanto na possibilidade do conhecê-lo, traduzi-lo e transformá-lo. ${ }^{9}$

Isso posto, cabe destacar brevemente alguns pensadores que subsidiam as reflexões sobre a arte, a partir de revisões da literatura. ${ }^{6-11}$ Em Platão, vê-se um ambiente propicio para pensá-la pelo viés da reflexão não propriamente da arte, mas do belo, das idéias e do ideal. Na Estética de Hegel ela aparece como fenômeno ligado à história e ao sintoma da vida contínua, obstinada, do espírito, indicando aí o seu desenvolvimento. Nietzsche, acerca do Nascimento da Tragédia, a enxerga como potência da própria vida, entrelaçada pelo delírio dionisíaco e pela beleza apolínea, eivada de embriaguez da alma. Aristóteles nos fala da arte da mimesis, em sentido de metáfora da vida, com finalidades do prazer e do deleite estético. Em busca de alguns paradoxos fundadores da arte, Kant propõe quatro momentos do julgamento estético, quais sejam: a satisfação desinteressada, a subjetividade universal, a finalidade sem fim e a necessidade livre. Tais premissas destituem a 
arte de sua necessidade utilitária, colocando-a na posição de autonomia capaz de inspirar as utopias humanas. Nesse sentido, a obra de arte será desinteressada, não submetida ao conceito, universalmente reconhecida por sentimentos individuais e coletivos, diretamente comunicável. ${ }^{9}$

Resgatar a soberania da arte em relação aos discursos da razão instrumental e das tramas da indústria cultural, espoliadora da criatividade humana, é a principal preocupação em Adorno, um dos integrantes da Escola de Frankfurt. ${ }^{6,12} \mathrm{Em}$ sua crítica à modernidade, essa vertente teórica denuncia a submissão da cultura à industrialização, à redução da filosofia e da ciência ao positivismo, bem como a rendição da arte aos desígnios do mercado. Adorno vê na obra de arte de vanguarda, em especial na música, o último reduto de uma razão esclarecida, livre da contaminação instrumentalizada. A educação pensada a partir da teoria crítica, ${ }^{13} \mathrm{em}$ especial nas reflexões sobre os limites da ciência moderna e da indústria cultural, subsidia a formação de sujeitos autônomos, criativos e participativos. A linearidade da racionalidade cartesiana, positivista, instrumental e tecnicista tem influenciado as formas de conhecer na modernidade, alinhando-se ao modo capitalista de forjar conhecimentos úteis ao mercado.

Dentre as atualizações marxistas realizadas recentemente sobre o capitalismo, encontra-se a tese polêmica de que se deve mudar o mundo sem tomar o poder. Discute-se a relação entre a crítica e o fazer humano, em sentido emancipatório. ${ }^{14}$ Colocase a idéia, inspirada em correntes filosóficas, de que só se pode conhecer com certeza o que se cria, produto do sujeito cognoscente. Nestes termos, o conhecimento teria como objetivo principal resgatar a subjetividade, recobrando o que fora expoliado no processo de trabalho. Seria ainda a reapropriação do objeto pelo sujeito, que passaria a negar sua externalidade, reconhecendo-o como parte de si. A ruptura da dominação, corporificada na forma de podersobre, dar-se-ia pelo movimento emancipatório do poder-fazer, constituindo-se em luta para revelar o potencial humano por meio do fazer criativo, contrae-mais-além do trabalho alienado. ${ }^{14}$

A partir dessas teorizações, entende-se que a arte, como expressão da sensibilidade mediadora de transcendências do espírito, pode estimular criatividades que recriem as possibilidades de compreensão do mundo, para além do capital.11,15 Busca-se um sentido para educação capaz de reconfigurar a separação entre Homo faber e Homo sapiens, resgatando-lhe o sentido estruturante na relação com o trabalho e com a própria vida, ${ }^{16}$ ampliando-lhe as possibilidades criativas. Entende-se igualmente que as dimensões humanas do ludens, ou do lúdico, e do demens, demoníaco, precisam de revisões nos processos formativos, despertando sentidos que ultrapassem o formalismo das instituições de ensino, fortemente calcadas em relações de poderes que aprisionam almas criadoras. ${ }^{17}$

O desenvolvimento da crítica e da capacidade criativa humana pelo intermeio da arte, ou pela dimensão estética da aprendizagem, se forja em concepções críticas da educação. ${ }^{17-22}$ Tais processos educativos se fundam em dinâmicas centradas na capacidade de abstração e de reconstrução de conceitos, de compreensões, de hábitos, de relações, de intervenções, da cultura e de valores referentes à vida das pessoas. A unidade teoriaprática é percebida como condição estruturante, uma vez que a vivência cotidiana subsidia os atos cognitivos, biológico, social e político do conhecer. Pressupõe-se intrinsecamente a autonomia dos sujeitos cognoscentes, entendida como síntese de muitas ajudas oferecida às pessoas para que essas se tornem protagonistas de suas vidas, ao invés de meros objetos manipuláveis. ${ }^{23}$ Há de se investir na vontade de poder vociferada por Nietzsche, ${ }^{24}$ vislumbrada como potencia do transcender, do ir contra e mais além, da ultrapassagem dos próprios limites, reinventando-se como pessoa e cidadão.

Nesse ambiente fomentador de mudanças, o conhecimento é visto como uma dinâmica viva de produzir interpretações, significados, críticas e formas de participar da realidade. Conhecer é, sobretudo, reconstruir possibilidades de conviver, de atuar e de interagir com o planeta, concebendo a disrupção e a provisoriedade como cerne. Em sentido emancipatório, vê-se que mesmo poder do conhecimento que sustenta a mais-valia relativa, explorando a criatividade humana, pode vir a se constituir numa força de subversão, por dinâmica interna e latente no mesmo ato subjulgante. ${ }^{15} \mathrm{~A}$ virtualidade que surge coloca a inovação, possibilitada pelo entrelaçamento da arte com a educação, como um elemento vitalmente político, capaz de alimentar e confrontar poderes.

\section{A TRAVESSIA DA ARTE NO ENSINO DA ADMINISTRAÇÃO EM SAÚDE: AS INTERMITÊNCIAS DA MORTE E A GES- TÃO DO SUS}

"E no dia seguinte, ninguém morreu". 4:1 Com essa frase, José Saramago inicia e termina 
as intermitências da morte, obra que descreve a realidade de um país em que as pessoas param de morrer. As repercussões sociais, políticas, econômicas e ontológicas do recesso da morte é brilhantemente relatada em detalhes. Reflete-se sobre a essencialidade da morte para a vida, bem como da arte para o ideal ético humanista. No percurso, o autor retrata ricas experiências vividas por uma nação diante da suspensão temporária da finitude humana. Dentre elas, a superlotação dos hospitais, a crise financeira da previdência social, as falências dos planos de seguro de vida e dos negócios funerários, as Maphias que corrompem os ideais de democracia, escrita com ph para destacar-lhe a excentricidade, bem como os impasses do governo, da Igreja e da sociedade para lidar com o insuportável da vida eterna. Esse é o pano de fundo sobre o qual se propõe o estudo da gestão do sistema e serviços de saúde, objeto da disciplina administração em saúde. A matéria tem como tem como propósito conhecer o funcionamento do sistema de saúde no que se refere à gestão da rede assistencial, a articulação entre os níveis de atenção, os fluxos e a trajetória do usuário nos serviços de saúde dos distritos sanitários do SUS de Belo Horizonte-MG.

A metodologia pedagógica proposta na disciplina pauta-se em abordagens interacionistas, de cunho dialógico, e na teoria crítica da Escola de Frankfurt. Centra-se na construção do conhecimento a partir dos sujeitos, ao invés da simples assimilação de registros e de informações. As técnicas de ensino utilizadas procuraram motivar a capacidade reflexiva, de criação, de abstração ética e estética nos discentes. Adota-se a arte como linguagem fundamental para as experiências de aprendizagem transcendentes, realizadas por meio de processos de mobilização interior. A intenção é despertar o potencial cognitivo, sensitivo, de associações, da imaginação e dos processos intuitivos que informam o próprio modo de conhecer das pessoas.

Inicia-se pela dinâmica abrigo. Um gestor para salvar o mundo, que tem como objetivos: introduzir a discussão sobre a gestão do sistema e serviços de saúde, considerando as intermitências da morte; refletir sobre as responsabilidades dos profissionais de saúde diante da vida e morte das pessoas, nos diversos espaços de atuação; e apresentar a proposta da disciplina. Simula-se uma situação em que o planeta terra está prestes a ser destruído pela bomba atômica. Há apenas uma cidade que escapará, construída com a mais alta tecnologia de proteção, em que cabem sete pessoas, além do aluno, representando o gestor do sistema de saúde de município. As pessoas escolhidas farão parte da primeira comunidade de uma nova civilização, fundada em outras bases e valores, calcada em novas formas de conviver.

Lista-se os 15 candidatos que querem ser incluídos: - físico nuclear, 40 anos, cientista, ele só vai com sua bomba; - advogado, 45 anos, criminalista e jurista renomado, insiste em levar a esposa; - esposa do advogado, 65 anos, dona de casa, acabou de sair do hospício, eles querem ficar juntos; - menina, 16 anos, portadora de necessidades especiais; - poeta, músico e artista, 33 anos, homossexual convicto; - padre ortodoxo, é contra a legalização do aborto, o uso da camisinha e o casamento gay; - ex-prostituta, agente comunitária de saúde, 30 anos, fez curso de cabeleireiro e maquiagem, quer abrir seu próprio negócio; - intelectual, filósofo, 50 anos, tentou suicídio 3 vezes, defende a eutanásia, o aborto e a livre expressão de idéias; - médico, 40 anos, empresário e dono de um grande hospital, burla o sistema público de saúde para realizar cirurgias nos seus pacientes particulares; - violoncelista, 49 anos, tem um cão viralata, acredita que a morte é uma expressão da vida; - administrador, 36 anos, modelo, galã de novela, tri-atleta, tem uma construtora, acabou de dar um golpe no seu sócio e está milionário; - enfermeira, dona de casa, foi torturada pelo regime militar, 60 anos, sofre de depressão crônica; - menina 32 anos, universitária, milita no movimento contra a discriminação de gays, lésbicas e transgêneros; - jovem, 35 anos, agrônomo, ecologista, está com aids, recusa-se a tomar o coquetel por acreditar no poder da mente e - a morte. Propõe-se aos estudantes que eles, como gestores, escolham as pessoas que irão se salvar. $\mathrm{O}$ processo de discussão deve se basear no consenso, a votação não é permitida. No desenrolar da técnica, a mediação dos professores permanece isenta de comentários, instigando a livre argumentação de idéias, carreadas dos valores da turma.

No geral, os resultados retratam os conceitos e preconceitos dominantes na sociedade capitalista. A preocupação exacerbada com a reprodução da espécie, com a juventude, com a produtividade, com o utilitarismo, com o padrão de beleza dominante e com a morte como falência da vida aparecem nos discursos inflamados dos alunos. O consenso, que deveria prevalecer nos convívios democráticos, é difícil de acontecer, comprometendo o número de pessoas que se salvam. Porém, há concordância sobre a negação da entrada da morte no abrigo, desnecessária para o mundo novo, 
dizem. Durante os debates, as ordens dos discursos dominantes são explicitadas. A arte, o amor, a diferença e as diversas formas de liberdades humanas são sacrificadas em prol do domínio da norma, da produtividade e de uma competitividade desigualmente injusta, principalmente para as minorias sociais.

O mediador, que até então ficara calado, destaca tudo o que fora falado durante as discussões, convidando os alunos a refletirem, intimamente, sobre as sérias questões levantadas. $\mathrm{O}$ choque de se flagrar defendendo idéias opressivas, pouco refletidas, inebriadas pelo cotidiano mecanizado da vida, emudece a turma. Há um misto de raiva, perplexidade, consciência, mea-culpa e tristeza entre os jovens participantes. Alguns percebem o significado da técnica rapidamente, entrando em auto-reflexão profunda. Outros, abreviados pela imaturidade, encaram a dinâmica com revolta, repercutindo nas demais atividades previstas, sendo esse um desafio que as professoras tiveram que enfrentar ao longo da disciplina.

Finda a aula, propõe-se a realização do diálogo entre a obra literária - As intermitências da morte, ${ }^{4}$ e os conteúdos da disciplina, distribuídos em duas unidades: gestão e organização do SUS e gerência dos serviços de saúde. Um município fictício é criado, inicialmente com os escolhidos do abrigo, depois acrescido da população da cidade real, por meio das atividades teóricas e práticas previstas na disciplina. Essas incluem o reconhecimento da rede de serviços do SUS nos diversos níveis de atenção, começando pela rede básica e o território-processo, passando pelos serviços de média e de alta complexidade. Ao longo das vivências de ensino-aprendizagem, os alunos são estimulados a refletirem sobre os desafios da gestão do SUS em diálogo com a ficção literária, identificando similitudes com a realidade das políticas de saúde no Brasil. A metáfora da vida que imita a arte é lançada como desafio no primeiro dia de aula, tendo como fio condutor as discussões sobre a morte, o viver e o morrer humano.

Por meio do Ciclo de Debates criado para subsidiar as discussões da disciplina, desenvolvem-se três atividades, entrelaçando cinema e literatura. Primeiramente faz-se um debate sobre o filme documentário Sickos- \$O \$ saúde, de Michel Moore, discutindo-se a viabilidade de sistemas de saúde universais em contextos mercadológicos. A atividade acontece numa sala de cinema da cidade ou no auditório da EE/UFMG, com posterior debate entre os alunos, os professores, os profissionais de saúde, os técnicos e os gestores da SMSA-BH. A linguagem estética do cinema subsidia planos e quadros de emoções difíceis de serem conseguidos por meio das técnicas tradicionais de ensino.

A saída da sala de aula, o ritual de ida ao cinema, o convívio entrelaçado entre o prazer, a vida e o trabalho, tudo contribui para as ricas discussões que se seguem. A interface entre a ficção e a realidade subsidia os aprendizados, propondo abstrações para além do instrucionismo. No embalo da arte e da educação, articula-se o documentário em tela, as leituras literárias, científicas e técnicas realizadas, as vivências nos serviços de saúde, bem com a construção do município recém criado, permeado de elementos inventados e retratados da realidade. Esse é um momento importante tanto para apreensão dos conteúdos, quanto para as discussões políticas que envolvem a saúde como um bem público e um direito social, não sujeito às intempéries do mercado. Vê-se aqui um amadurecimento da turma, que passa a refletir sobre suas responsabilidades como cidadão, eventual gestor, gerente e futuro profissional da saúde.

O segundo momento do ciclo de debates ocorre por meio de um painel em que a obra literária de José Saramago, centrada no livro escolhido, é discutida por uma professora e pesquisadora da Faculdade de Letras da UFMG. Pode-se dizer que nesse ponto os alunos verdadeiramente entram no "espírito da coisa". A abordagem de outra área, trazendo elementos e compreensões diversas, amplia o horizonte das reflexões criativas dos alunos. A riqueza da obra de arte é explorada em múltiplos olhares, o devir das sensibilidades e dos afetos se alarga, produzem-se sentidos muito além das formalidades acadêmicas. A interdisciplinaridade é o ponto alto da vivência. A área da saúde se alimenta das letras eivadas de textos e intertextos. As narrativas das letras por sua vez, embebem-se do contexto do SUS e da gestão das políticas de saúde, produzindo-se ricos aprendizados nos participantes.

Percebe-se que a partir da discussão interdisciplinar a motivação dos alunos se eleva às alturas. As idéias criativas para a difícil tarefa de articular administração em saúde com a literatura, dantes tão impossível, agora flui num frêmito empolgado, próprio da juventude. Antes do momento final, cada grupo de alunos apresenta o projeto do diálogo entre as intermitências da morte e a gestão do SUS aos professores da disciplina. A proposta deve conter o objeto de reflexão a partir dos desafios vivenciados no SUS e a leitura do livro; os 
objetivos do diálogo proposto; uma justificativa contendo análise comparativa entre as intermitências da morte e os problemas identificados na rede assistencial, com revisão de literatura; bem como a metodologia, prevendo as estratégias que serão utilizadas, envolvendo os elementos artísticos a serem apresentados.

Para aquecer ainda mais o desafio, o prêmio "Jovem Gestor do SUS" é entregue ao melhor trabalho apresentado durante o simpósio, na opinião de um júri formado por técnicos da SMSA-BH e por professores da área de humanas. No regulamento do prêmio constam os aspectos a serem contemplados nas apresentações, quais sejam: - a proposta final deve explicitar a interface entre a obra literária e os desafios da gestão do SUS; - a forma de apresentação deve contemplar algum componente artístico; - o tempo total de apresentação não deve ultrapassar 20 minutos; em algum momento, a frase "E no dia seguinte, ninguém morreu" deverá aparecer. Os critérios a serem considerados na avaliação são: - nível de aprofundamento da análise sobre a gestão do SUS; - clareza da articulação entre a obra literária e os desafios da gestão do SUS; - originalidade das apresentações; - cumprimento do tempo das apresentações. *

A etapa final da disciplina e do ciclo de debates culmina com as apresentações artísticas dos alunos. É um momento emocionante para todos, em que a criatividade e a livre expressão do ser dialogam com os conteúdos técnico-científicos da área da saúde. Os talentos individuais e coletivos são explorados. Aprende-se outras habilidades, como trabalho em equipe, gestão de recursos humanos e materiais, articulação de redes sociais para realização de projetos, disciplina e capacidade de elaboração. Supera-se os limites desde o ensaio das apresentações, passando pela confecção dos objetos, vídeos e cenários que serão utilizados, até a estréia dos espetáculos. O que move o interesse e a disposição dos alunos é superior a mera necessidade de nota. $\mathrm{O}$ ímpeto da busca se nutre da utopia de realizarem-se como sujeitos de projetos próprios, autônomos e criadores de expressões de vida.

Os temas de diálogo até agora apresentados foram a superlotação dos hospitais do SUS e a situação de não morte descrita no livro; a trajetória dos usuários entre os municípios em busca de atendimentos e o cruzamento da fronteira pelos personagens do livro, para que seus entes possam morrer do outro lado do país; a necessidade da morte para vida humana e os desafios vivenciados pelos gestores, gerentes e profissionais do SUS; o encontro da morte com a arte e as possibilidades para a vida humana; o julgamento ético da morte pela suspensão das suas atividades, gerando caos no sistema de saúde; as repercussões do envelhecimento da população sobre o acesso aos serviços de saúde e a condição de não-morte discutida na ficção.

Em geral, os próprios alunos editam os vídeos, escrevem, ensaiam e encenam as peças teatrais, tocam instrumentos musicais, dançam, confeccionam bonecos de fantoches, elaboram os textos dos diálogos e os apresentam em cena. Eles ainda concebem, produzem e montam exposições de arte. Encenam mímicas, recriam músicas e se inspiram nas várias manifestações culturais para comporem seus espetáculos, eivados de si e da vontade de realizar desejos. Pelo vivido até aqui, parece que a morte consegue lhes tocar a fundo, despertando singularidades da vida, viável pelo enlace da arte com a educação.

Despertar a vontade de transcender do sujeito, ampliando-lhe as compreensões e as possibilidades éticas do mundo. Fomentar-lhe projetos próprios de vida e de desenvolvimento, em sentido individual e coletivo. Talvez sejam esses os propósitos da dimensão estética da educação. Em busca de alguns caminhos possíveis, fala-se nas funções pedagógicas da arte. ${ }^{25}$ A primeira, é que a arte apresenta eventos pertinentes à esfera dos sentimentos, não acessíveis ao pensamento discursivo. Na experiência estética, a imaginação rompe os limites impostos pela intelecção, instaurando possibilidades de autonomia inscritas no conhecimento mediado pelo afeto. Advém daí o segundo fator pedagógico, qual seja, a agilização da imaginação, sua libertação do pensamento rotineiro, programado, linear, mecanizado. Numa sociedade que elegeu o racionalismo instrumental calcado no empirismo balconiano como única forma de conhecer, ${ }^{13}$ o intento da inventividade aparece como utopia realizável.

O terceiro fator educativo da arte seria a perspectiva de desenvolver sensibilidades adormeci-

* O primeiro ciclo contou com recursos do Colegiado de Graduação e do Departamento de Enfermagem da EE/UFMG. O segundo obteve financiamento do Programa de Apoio a Eventos da Pró-reitoria de Extensão da UFMG, do Centro de Extensão e Colegiado de Graduação da EE/UFMG. 
Pires MRGM, Spagnol CA, Brito MJM, Gazzinelli MFS, Montenegro LC

das, no melhor estilo da educação dos sentidos, ${ }^{26}$ em que o sentimento é convidado a se apurar. $\mathrm{O}$ quarto elemento toma de assalto o viés aberto da obra de arte, que se completa na intersubjetividade do encontro, em constante fazer-se criativo. Essa característica imprime o movimento do vir-a-ser nos processos educativos inerente ao impossível, provocado pela experiência sensível. A quinta vertente pedagógica evoca as compreensões do mundo distantes do nosso cotidiano, tornada possível pelo acesso ao sentimento humano.

Tendo em vista que a expressão cultural de uma época se inscreve pelas vias do artístico, contemplando a diversidade da existência humana, o significado cultural da arte constitui-lhe a sexta função educativa. Esse elemento é importante se levarmos em conta as críticas do multiculturalismo à educação, em que o respeito às diferenças aparece como uma questão de cidadania a ser formada desde os bancos escolares, transbordando para o exercício democrático. ${ }^{27}$ Em decorrência, as vivências interculturais viabilizadas pela arte integram a sétima função educativa. Por fim, o elemento utópico envolvido na criação artística lhe surge como oitavo fator, por meio do qual a emancipação humana se torna possível.

Retornando à experiência, a dialética da vida e da morte subsidia reflexões epistêmicas, ontológicas e estéticas que ultrapassam as opiniões cotidianas sobre o real. Da mesma forma, investir no inusitado da arte para a formação de sujeitos criativos parece ser uma saída inspiradora para os sonhos humanos, sempre tão incertos, improváveis, mortais e por se fazer.

\section{OS GANHOS DA APRENDIZAGEM: (...) NÃO TINHA NOÇÃO DA MINHA PRÓPRIA CAPACIDADE DE CRIAÇÃO E PERCEPÇÃO**}

Após duas experiências dialogando arte e educação na administração em saúde, muitas lições foram aprendidas. Começando pelos professores, há de se destacar a dificuldade em sintonizar as falas e os entendimentos de uma disciplina que conta com cinco ou seis professores, sendo pelo menos dois substitutos. As diferentes trajetórias de cada um, dificulta a harmonia necessária à implementação de uma proposta que pretende articular tantas vivências, cenários de aprendizagens e campos de conhecimento. $\mathrm{O}$ inusitado da experiência gerou receios no corpo docente e discente, sempre tão acostumados às respostas certas. Porém, a vontade de fazer diferente parece ter sido superior aos atropelos operacionais, emocionando a todos no final, não sem os resquícios a serem consertados na turma seguinte.

$\mathrm{Na}$ segunda experiência, alguns ajustes foram realizados, principalmente no sentido de melhor articular os conteúdos teóricos com a proposição artística. Foram elaborados roteiros orientadores para cada atividade, que serviram de bússola para alunos e professores. Inovou-se também em algumas técnicas de ensino, como a realização de uma gincana educativa para fixação dos conteúdos. Com isso, recuperou-se um aprofundamento no entendimento teórico da disciplina, objetada nas avaliações da primeira turma. Em compensação, o foco nas abstrações que a obra literária enseja foi menos intenso o que repercutiu nas apresentações finais.

Ou seja, fazendo um balanço entre as duas experiências, parece que na primeira pecamos mais no conteúdo teórico, talvez mais empolgadas e preocupadas com o inusitado da arte na disciplina. Na segunda, tentamos corrigir isso, e virtualmente nos desprendemos um pouco de melhor estimular as inspirações literárias. O resultado é que as apresentações da primeira turma emocionaram muito pela arte, mas priorizaram menos o diálogo com os conteúdos da disciplina. A seguinte, por seu turno, aperfeiçoou a profundidade da interface, porém aqueles grupos que mais emocionaram tenderam a permanecer no escopo da arte. Questiona-se se esse equilíbrio de fato existe, ou se não passam de expectativas aprisionadoras de sentidos, tipicamente disciplinares, que nos afastam das transcendências do espírito.

O que mais preponderou nos depoimentos finais dos alunos foi a surpresa com os próprios talentos e as capacidades criativas, o que sintetiza os objetivos buscados na conversa entre a arte e a educação. Porém, como é comum às manifestações repletas de afetos, parece que algo de incapturável acontece no momento das apresentações. Perpetua-se o instante em que docentes e discentes simplesmente se esquecem do formalismo do ensino, conjugando-se nas realizações do humano. Talvez porque somos seres miméticos, almejantes de metáforas para a vida, "E no dia seguinte, ninguém morreu". . $^{4}$

** Depoimento extraído das falas dos alunos, realizadas ao final da disciplina. 


\section{REFERÊNCIAS}

1. Mandú ENT. Diretrizes curriculares e a potencializarão de condições para mudanças na formação de enfermeiros. Rev Bras Enferm. 2003 Jan-Fev; 1(1):348-50.

2. Silva LWS, Nazário ON, Silva SD, Martins CR. A arte na enfermagem: iniciando um diálogo reflexivo. Texto Contexto Enferm. 2005 Jan-Mar; 14(1):120-3.

3. Trezza MCS, Santos RM, Santos JM. Trabalhando educação popular em saúde com a arte construída no cotidiano da enfermagem: um relato de experiência. Texto Contexto Enferm. 2007 Abr-Jun; 16(2):326-34

4. Saramago J. As intermitências da morte. São Paulo (SP): Companhia das Letras; 2005.

5. Horkheimer M. O Eclipse da razão. São Paulo (SP) Centauro; 2002.

6. Adorno TW, Horkheimer M. Dialética do esclarecimento. Rio de Janeiro (RJ): Jorge Zahar; 1985.

7. Duarte Júnior JF. Porque Arte-Educação?. 6 $6^{\mathrm{a}}$ Ed. Campinas (SP): Papirus; 1991.

8. Foucault M. A hermenêutica do sujeito. São Paulo (SP): Martins Fontes; 2004.

9. Cauquelin A. Teorias da Arte. São Paulo (SP): Martins; 2005.

10. Nietzsche F. O nascimento da tragédia. São Paulo (SP): Companhia das Letras; 2007.

11. Aranha ML, Martins MHP. Filosofando. $3^{\text {a }}$ ed. São Paulo (SP): Moderna; 2003.

12. Freitag B. A teoria crítica ontem e hoje. São Paulo (SP): Brasiliense; 2004.

13. Torres CA, organizador. Teoria Crítica e sociologia política da Educação. São Paulo (SP): Cortez, Instituto Paulo Freire; 2003.
14. Holloway J. Mudar o Mundo sem tomar o poder. São Paulo (SP): Viramundo; 2003.

15. Mészaros I. A educação para além do capital. São Paulo (SP): Boitempo; 2005.

16. Gorz, A. Metamorfoses do trabalho: crítica da razão econômica. $2^{\mathrm{a}}$ ed. São Paulo (SP): Anna Blume; 2007.

17. Popkewitz TS. Lutando em defesa da alma: a construção do ensino e a construção do professor. Porto Alegre (RS): Artmed; 2001.

18. Freire P. Pedagogia do oprimido. $17^{\mathrm{a}}$ ed. Rio de Janeiro (RJ): Paz e Terra; 1987.

19. Santos BS. A crítica da razão indolente: contra o desperdício da experiência. $3^{\mathrm{a}}$ ed. São Paulo (SP): Cortez; 2001.

20. Morin E. Os sete saberes necessários à educação do futuro. $8^{\text {a }}$ ed. São Paulo (SP): Cortez; 2003.

21. Dalbosco CA. O cuidado como conceito articulador de uma nova relação entre filosofia e pedagogia. Educ Soc [online]. 2006. Set-Dez [acesso 2008 Dez 13]; 27(97):1113-35. Disponível em: http://www. scielo.br/pdf/es/v27n97/a03v2797.pdf

22. Maturana HR, Varela FJG. A árvore do conhecimento: as bases biológicas da compreensão humana. São Paulo (SP): Palas Athena; 2001.

23. Morin E. Método 5- A humanidade da humanidade. Porto Alegre (RS): Sulina; 2002.

24. Nietzsche F. A vontade de poder. Rio de Janeiro (RJ): Contraponto; 2008.

25. Júnior JFD. Fundamentos estéticos da educação. Campinas (SP): Papirus; 1988.

26. Alves R. Educação dos sentidos. Campinas (SP): Verus; 2005.

27. Santos BS, organizador. Reconhecer para libertar: os caminhos do cosmopolitismo multicultural. Rio de Janeiro (RJ): Civilização Brasileira; 2003. 